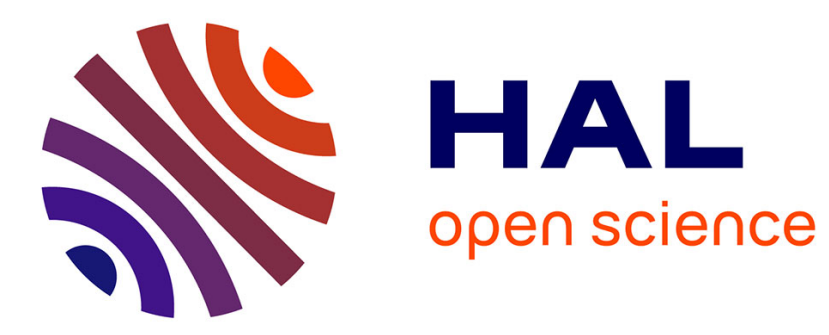

\title{
Diurnal water stress in sugar beet: Spectral reflectance measurements and modelling
}

\author{
F. Mark Danson, Yousef Aldakheel
}

\section{To cite this version:}

F. Mark Danson, Yousef Aldakheel. Diurnal water stress in sugar beet: Spectral reflectance measurements and modelling. Agronomie, 2000, 20 (1), pp.31-39. 10.1051/agro:2000100 . hal-00885989

\section{HAL Id: hal-00885989 \\ https://hal.science/hal-00885989}

Submitted on 1 Jan 2000

HAL is a multi-disciplinary open access archive for the deposit and dissemination of scientific research documents, whether they are published or not. The documents may come from teaching and research institutions in France or abroad, or from public or private research centers.
L'archive ouverte pluridisciplinaire HAL, est destinée au dépôt et à la diffusion de documents scientifiques de niveau recherche, publiés ou non, émanant des établissements d'enseignement et de recherche français ou étrangers, des laboratoires publics ou privés. 


\title{
Diurnal water stress in sugar beet: Spectral reflectance measurements and modelling
}

\author{
F. Mark DANSON*, Yousef Y. AlDAKHEEL \\ Telford Institute of Environmental Systems, Division of Geography, School of Environmental and Life Sciences, \\ University of Salford, Manchester M5 4WT, UK
}

(Received 8 June 1999; revised 27 September 1999; accepted 5 October 1999)

\begin{abstract}
An experiment was performed over a sugar beet (Beta vulgaris) crop to monitor change in spectral reflectance caused by diurnal water stress. Simultaneous measurements of crop canopy geometry and leaf water content were made in order to drive a bidirectional reflectance model. Diurnal change in crop spectral reflectance was found to be caused by change in solar position and by change in canopy geometry as the leaves wilted and drooped in response to short-term water stress. Comparisons between measured and modelled spectral reflectance showed that the model adequately described the crop reflectance before the onset of water stress but with wilting and a change in canopy geometry the measured and modelled reflectance diverged. It was concluded that the model does not account for changes in canopy gap fraction which may occur with water stress in sugar beet canopies.
\end{abstract}

water stress / sugar beet / spectral reflectance / modelling

Résumé - Stress hydrique diurne chez la betterave à sucre : mesures de réflectance spectrale et modélisation. Une expérience a été menée sur une culture de betteraves à sucre (Beta vulgaris) pour étudier l'effet d'un stress hydrique diurne sur la réflectance spectrale. Des mesures simultanées de la géométrie du couvert et de la teneur en eau des feuilles ont été effectuées afin de tester un modèle de réflectance bidirectionnnelle de la végétation. Il est apparu un changement de la réflectance spectrale du couvert consécutif au change-

Communicated by Gérard Guyot (Avignon, France)

* Correspondence and reprints

f.m.danson@salford.ac.uk 
ment de la position du soleil et à un changement de la géométrie du couvert lorsque les feuilles flétrissent et tombent à la suite d'un soudain stress hydrique. La comparaison entre les réflectances mesurée et simulée montre que le modèle décrit correctement la réflectance de la culture avant le début du stress hydrique mais qu'il y a divergence à partir du moment où il y a flétrissement. En conclusion le modèle ne prend pas en compte des changements de fractions de trous dans le couvert qui pourraient apparaître lors du stress hydrique.

\section{Stress hydrique / betterave / réflectance spectrale / modélisation}

\section{Introduction}

The growth of the UK sugar beet (Beta vulgaris L.) crop is monitored using remotely sensed data [12]. The current methodology involves the use of empirically-derived relations between a spectral vegetation index (VI) and canopy cover or leaf area index (LAI). This approach has been shown to work well during most of the growing season when canopy cover is the major determinant of canopy reflectance. However, in the late summer, the crop may experience short-term water stress on a diurnal cycle and change in canopy geometry may affect the VI/LAI relationship. Diurnal water stress is particularly marked during late July and August when the crop has reached near maximum leaf cover. In the morning when air temperatures are low the leaves of the plants are mostly erect. However, as temperatures increase, evapotranspirational demand exceeds the rate at which water can be supplied to the leaves and they begin to droop. By late afternoon most of the leaves may be nearhorizontal, depending on the severity of the stress. In general the plants recover over night after which the diurnal wilting cycle may begin again. The first aim of this work was to examine the impact of diurnal water stress on the spectral response of a sugar beet crop and to assess the impact on the estimation of canopy biophysical variables.

Recent advances in modelling the interaction of electromagnetic radiation with plant canopies have illustrated the potential of model inversion, as an alternative to the use of VI, to estimate canopy biophysical properties $[4,9]$. The interaction of electromagnetic radiation with vegetation canopies may be described using various types of canopy reflectance model which vary in complexity from simple empirically derived expressions to complex three dimensional mathematical models [7]. The simple models generally have only a few key parameters and may, with some restrictions, be inverted to determine canopy properties directly from remotely sensed data. The complex models normally describe the canopy architecture in some detail, contain several correlated parameters and are not generally suitable for inversion. Crop canopies may be modelled using a simple description of canopy architecture and therefore may be amenable to model inversion strategies [7]. However, a first requirement for successful inversion is that the model accurately describes canopy reflectance under a range of conditions. The second aim of this work was therefore to determine whether changes in the reflectance of a water stressed sugar beet crop could be modelled using radiative transfer models of leaf and canopy reflectance.

\section{Background}

For individual leaves there is normally a negative relationship between leaf water content and reflectance in near and middle infrared wavelengths $[1,6]$. This relationship is a direct function of the absorption characteristics of water which dominate the spectral response of vegetation in this region. In visible wavelengths absorption by leaf water is weak and change in reflectance resulting directly from leaf water loss will not be detectable. 
However, water stress may cause closure of the leaf stomates and reduction in $\mathrm{CO}_{2}$ supply, and this may in turn lead to increased visible reflectance [8].

From studies of the spectral response of complete canopies to water stress, it is clear that the effects of change in canopy geometry, as a result of wilting, may be at least as important in determining the spectral response of the canopy as the physiological effects within the leaf. For example in experiments on soybean and cotton canopies water stress gave rise to a more vertical leaf orientation which resulted in greater penetration of near infrared radiation and decreased reflectance [5, 8]; only small changes in visible reflectance were observed however.

Relatively few studies have examined the diurnal reflectance changes in vegetation canopies, however Andrieu and Boissard [2] made measurements over water stressed and non-stressed sugar beet crops from 09:00 to 16:00 h. For the nonstressed crop they found very little change in reflectance during the day in red and near infrared wavebands. For the water stressed crop they found an increase in red reflectance of $3 \%$, in absolute terms, from 09:00 to $14: 00$ followed by a $1 \%$ decrease to $16: 00$, but very little change in near infrared reflectance.

The combined Prospect+SAIL [9] model has been used successfully to model sugar beet canopy reflectance in a number of experiments [4,9]. It requires just three parameters to model leaf reflectance and four to model canopy reflectance. The combined model can describe change in leaf water content and leaf angle distribution which may occur as a result of water stress. It was therefore hypothesised to be suitable for modelling the changes in reflectance that occur with diurnal water stress. Andrieu et al. [3] compared measured and modelled reflectance from sunrise to sunset over a well-watered sugar beet crop. For the nadir measurements they observed an increase of 2-3\% in reflectance in a red waveband from early morning to midday and a similar decrease in the afternoon. Change in near infrared reflectance was less than $2 \%$ throughout the day. The Prospect+SAIL model underestimated reflectance by $2-5 \%$ in the red and near infrared wavebands but reproduced the diurnal pattern of reflectance change; a modified model which accounted for specular reflectance improved the fit between measured and modelled reflectance.

\section{Data collection}

Canopy spectral and biophysical data were collected over a water stressed sugar beet canopy in order to examine the diurnal change in reflectance and to compare the measured and modelled canopy reflectance spectra. The experiment was conducted on 18 August 1996 in a field of commercially grown sugar beet at Rostherne, Cheshire, England. The crop was planted in early April and at the time of the experiment was close to maximum leaf area index (LAI). Total rainfall in July 1996 was $29 \mathrm{~mm}$, significantly lower than the 18 -year average of $62 \mathrm{~mm}$. There was no rainfall in the week preceding the experiment so that soil moisture content was low. Temperatures reached a maximum of $29.6^{\circ} \mathrm{C}$ at 13:00 $\mathrm{h}$ on the day of the experiment.

\subsection{Spectral measurements}

Spectral measurements were obtained throughout the day over a single $1.5 \times 3 \mathrm{~m}$ plot oriented parallel to the row direction. An Analytical Spectral Devices (ASD) Fieldspec FR spectroradiometer was used to measure reflectance at 15 randomly selected points in the plot. The instrument was mounted on a mast at a height of $2 \mathrm{~m}$ to give a circular ground field of view of $18 \mathrm{~cm}$. A calibrated Spectralon panel was mounted on a tripod next to the plot and all measurements were made in sequential mode - panel followed by target, with a time difference of less than five seconds. A complete set of measurements was obtained within 10 minutes. Measurements of the diffuse skylight fraction were made at the beginning of each run and in addition measurements of soil reflectance were also obtained from a cleared area. A full set of spectral measurements were 
made at seven times during the day between 09:38 and 16:33 h.

Spectral reflectance was computed as the ratio of target to panel radiance and absolute reflectance computed using calibration data for the panel from the UK Natural Environment Research Council (NERC) Equipment Pool for Field Spectroscopy (EPFS). A correction for the non-Lambertian response of the reference panel was also applied based on the data from Rollin et al. [11]. This relationship was assumed to be independent of wavelength and was applied across the complete spectrum; no correction was made for the effect on panel reflectance of change in the amount of diffuse skylight during the day. Spectral data collected at 11:00 were omitted because of instrument malfunction and all data at wavelengths between 1350 and $1450 \mathrm{~nm}$ and 1800 and $1960 \mathrm{~nm}$ were deleted because of high atmospheric absorption and consequent noisy signal.

\subsection{Biophysical measurements}

The collection of biophysical data involved some destructive sampling and so the measurements were made in a separate plot adjacent to that used for spectral data collection. Measurements of leaf water content and leaf inclination angle were obtained for four or five plants simultaneously with spectral data collection. Leaf disks were punched from four or five leaves (leaf order 3, 5, 7,
9 and 11 where present) and transferred to airtight plastic bags. The samples were later weighed, oven dried and reweighed to obtain leaf water content. Leaf inclination angle was measured manually on the same number of leaves using an inclinometer. Changes in canopy geometry were clearly visible soon after midday.

The LAI of the plot was determined by measuring the length and width of a sample of leaves within the plot and using previously established allometric equations to estimate total plant leaf area and thereby plot LAI. Average chlorophyll content was determined using spectrophotometric techniques on a sample of ten randomly selected leaves.

\section{Application of Prospect+SAIL model}

The combined Prospect+SAIL model was used to simulate the diurnal change in spectral reflectance due to water stress. Average chlorophyll and leaf water content were obtained from the measured data and a value of 1.5 was used for the leaf structure parameter, which describes the level of scattering within the leaf, based on the results of previous work (Tab. I) [4, 9]. The leaf size parameter was obtained from the ratio of canopy height to average leaf size and was used to compute the hot-spot parameter [10].

Table I. Variables used to drive combined Prospect+SAIL model.

\begin{tabular}{|c|c|c|c|}
\hline & Variable & Unit & Value \\
\hline Prospect variables & $\begin{array}{c}\text { Leaf chlorophyll content }(\mathrm{Cab}) \\
\text { Leaf water content }(\mathrm{Cw}) \\
\text { Leaf structure index }(\mathrm{N})\end{array}$ & $\begin{array}{l}\mu \mathrm{g} \cdot \mathrm{cm}^{-2} \\
\mathrm{~cm} \\
\text { none }\end{array}$ & $\begin{array}{c}39 \\
0.019-0.022 * \\
1.5\end{array}$ \\
\hline SAIL variables & $\begin{array}{c}\text { Leaf area index (LAI) } \\
\text { Average leaf inclination angle } \\
\text { Leaf size parameter } \\
\text { Soil reflectance } \\
\text { Diffuse irradiance } \\
\text { Solar zenith angle }\end{array}$ & $\begin{array}{c}\text { none } \\
\text { degrees } \\
\text { none } \\
\% \\
\% \\
\text { degrees }\end{array}$ & $\begin{array}{c}2.17 \\
44-31^{*} \\
0.3 \\
\text { measured* } \\
\text { measured* } \\
67-40\end{array}$ \\
\hline
\end{tabular}

\footnotetext{
$*=$ time-dependent variables defined by their measured value in the field.
} 


\section{Results}

Analysis of the canopy biophysical data (Tab. II) showed that there was no significant change in leaf water content during the day but a change in mean leaf inclination angle of $13^{\circ}$ from $44^{\circ}$ at $09: 38$ to $31^{\circ}$ at 16:44 (Fig. 1). This suggests that the crop experienced only "mild" water stress. Further analysis focussed on (i) the change in spectral reflectance of the crop during the day and (ii) comparison of measured and modelled reflectance during the day.

Table II. Change in solar position, leaf water content and mean leaf inclination angle.

\begin{tabular}{ccccc}
\hline $\begin{array}{c}\text { Time } \\
(\text { GMT) }\end{array}$ & $\begin{array}{c}\text { Solar } \\
\text { zenith } \\
\text { angle }\left(^{\circ}\right)\end{array}$ & $\begin{array}{c}\text { Solar } \\
\text { azimuth } \\
\text { angle }\left(^{\circ}\right)\end{array}$ & $\begin{array}{c}\text { Mean } \\
\text { leaf water } \\
\text { content }(\mathrm{cm})\end{array}$ & $\begin{array}{c}\text { Mean } \\
\text { leaf } \\
\text { angle }\left(^{\circ}\right)\end{array}$ \\
\hline 0938 & 48.31 & 133 & 0.019 & 44 \\
1052 & 41.96 & 157 & 0.018 & 43 \\
1202 & 40.12 & 183 & 0.020 & 43 \\
1324 & 43.86 & 212 & 0.019 & 40 \\
1433 & 50.86 & 233 & 0.019 & 37 \\
1535 & 58.95 & 249 & 0.020 & 35 \\
1633 & 67.31 & 262 & 0.022 & 31 \\
\hline
\end{tabular}

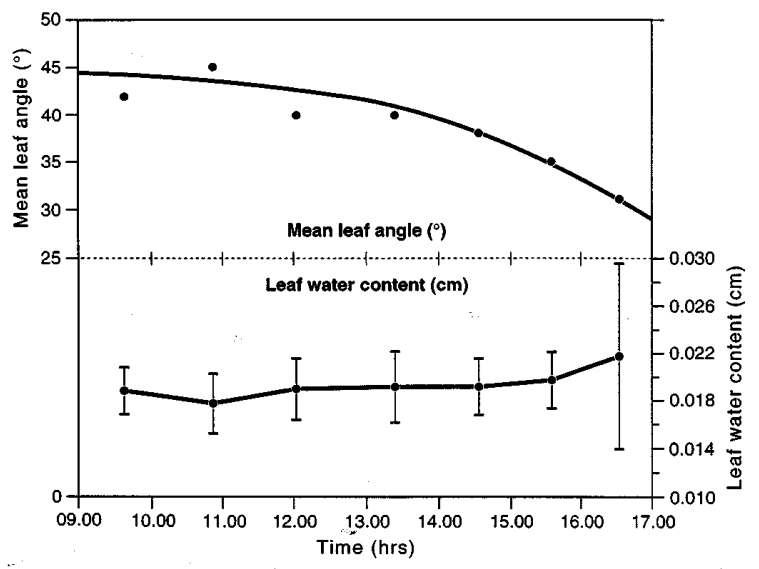

Figure 1. Change in crop mean leaf angle and leaf water content during the experiment.

\subsection{Spectral reflectance change}

Change in spectral reflectance during the day was relatively small (Fig. 2) with the largest absolute difference of about $5 \%$ in the $800 \mathrm{~nm}$ region. Change in red reflectance $(670 \mathrm{~nm})$ showed some symmetry about solar noon, as observed in previous experiments [3], with an increase of $1 \%$ in the morning and a similar decrease in the afternoon (Fig. 3). Change in near infrared reflectance showed no symmetry but a decrease of $5 \%$ from morning to afternoon (Fig. 3). The data analysis aimed to test for statistically significant differences

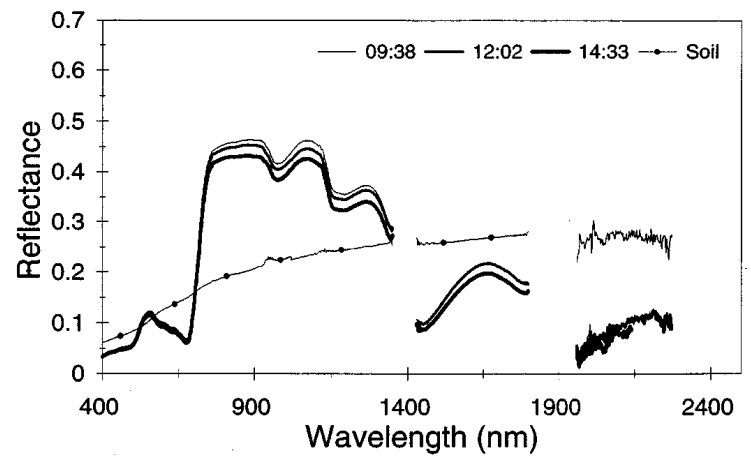

Figure 2. Change in spectral reflectance during the experiment. For clarity only data for 09:38, 12:02 and 14:33 h are shown.

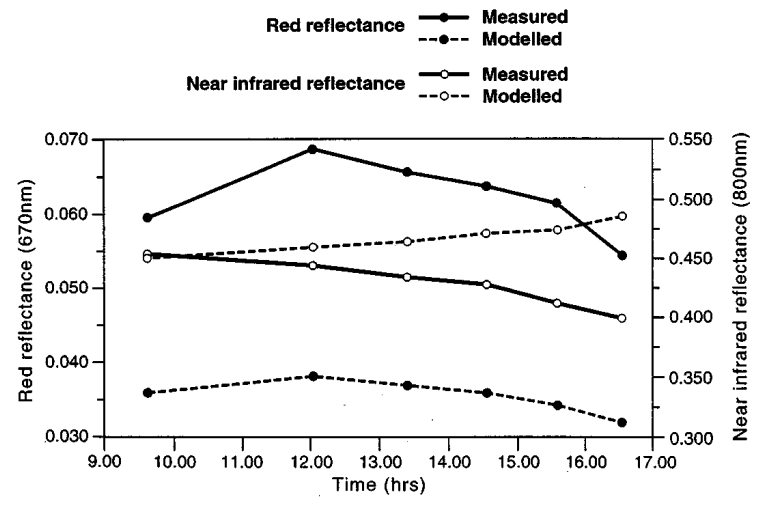

Figure 3. Change in measured and modelled red and near infrared reflectance during the experiment. 
in reflectance using the two-sample t-test, and in particular differences between the morning (09:38), midday (12:02) and afternoon (14:33) measurements.

\subsubsection{Morning (09:38) and midday (12:02) reflectance differences}

A two-sample t-test was applied to test for differences in mean reflectance between 09:38 and 12:02 where the change in water content and average leaf angle was small $\left(44^{\circ}\right.$ to $\left.43^{\circ}\right)$ but solar zenith angle decreased from $48^{\circ}$ to $40^{\circ}$. The t-spectra showed that there was a significant increase $(\mathrm{p}<0.05)$ in reflectance (negative $\mathrm{t}$-statistic) in visible wavelengths up to approximately $650 \mathrm{~nm}$. At longer wavelengths there was no significant difference in reflectance between the morning and midday (Fig. 4).

\subsubsection{Midday (12:02) and afternoon (14:33) reflectance differences}

From 12:02 to $14: 33$ average leaf angle decreased from 43 to $37^{\circ}$ and solar zenith angle increased from $40^{\circ}$ to $51^{\circ}$. The t-spectrum showed that there was a significant decrease $(p<0.05)$ in reflectance (positive t-statistic) in visible, near infrared and middle infrared wavelengths, except for the 400-450 nm region (Fig. 4).

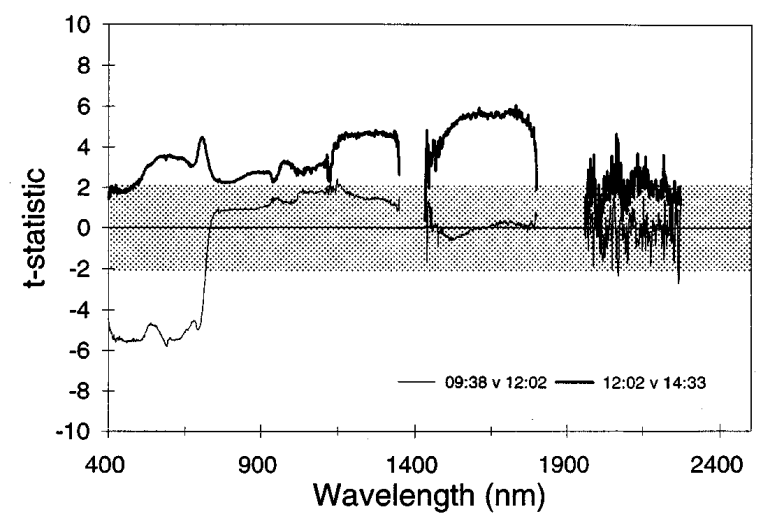

Figure 4. Spectra of t-statistic to test for difference in mean reflectance between morning and midday (09:38 and 12:02), and midday and afternoon (12:02 and 14:33). Shaded area at $=+/-2.1$ shows the region where $t$ is not significant $(p<0.05)$.

\subsubsection{Morning (09:38) and afternoon (14:33) reflectance differences}

The morning (09:38) and afternoon (14:33) spectra were compared in an attempt to isolate the effect of change in solar zenith angle from change caused by change in leaf angle distribution. At these two times average leaf angle was significantly different $\left(44\right.$ and $\left.37^{\circ}\right)$ but solar zenith angle was similar (48 and $51^{\circ}$ respectively). The t-spectrum showed that there was a significant increase in visible reflectance and a significant decrease in near infrared and middle infrared reflectance between the morning and afternoon (Fig. 5).

\subsubsection{Interpretation}

These results show that diurnal change in canopy reflectance is affected by both shadowing and canopy geometry changes. The increase in visible reflectance from morning to midday was caused by a decrease in the amount of shadow within the canopy as solar zenith angle decreased (solar elevation increased). Shadowing is less important in the near infrared and the difference in reflectance for these times was not significant. From midday to afternoon the increase in shadowing accounts for the decrease in canopy reflectance in visible wavelengths although the flatter orientation of the leaves may have reduced the size of this

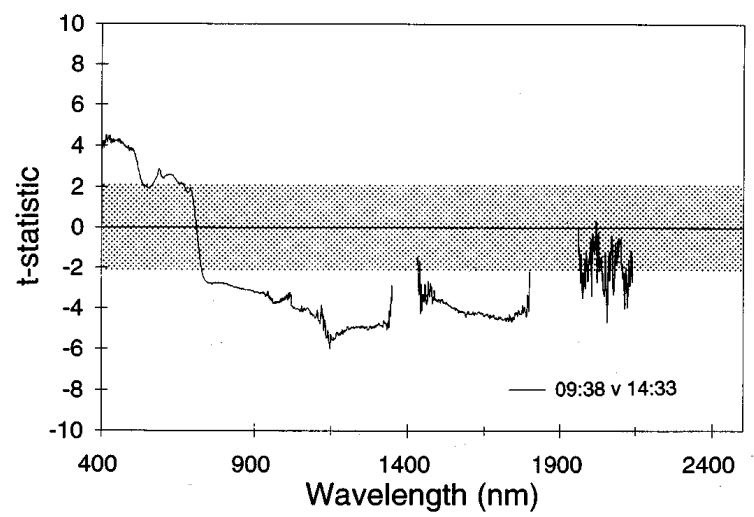

Figure 5. Spectra of t-statistic to test for difference in mean reflectance between morning and afternoon (09:38 and 14:33). Shaded area at $\mathrm{t}=+/-2.1$ shows the region where $\mathrm{t}$ is not significant $(\mathrm{p}<0.05)$. 
effect. The significant decrease in near infrared reflectance must be caused by some other mechanism; with a decrease in average leaf angle, an increase in multiple scattering and reflectance would be expected. It is hypothesised that as water stress progressed, the leaves in the canopy drooped and folded causing an increase in the canopy gap fraction. This will have increased the amount of soil background seen by the sensor and, given that the soil was darker than the leaves in the near infrared, this will have caused a decrease in measured reflectance at these wavelengths.

\subsection{Comparison of measured and modelled reflectance}

At 09:38 the measured and modelled reflectance were similar with maximum reflectance differences
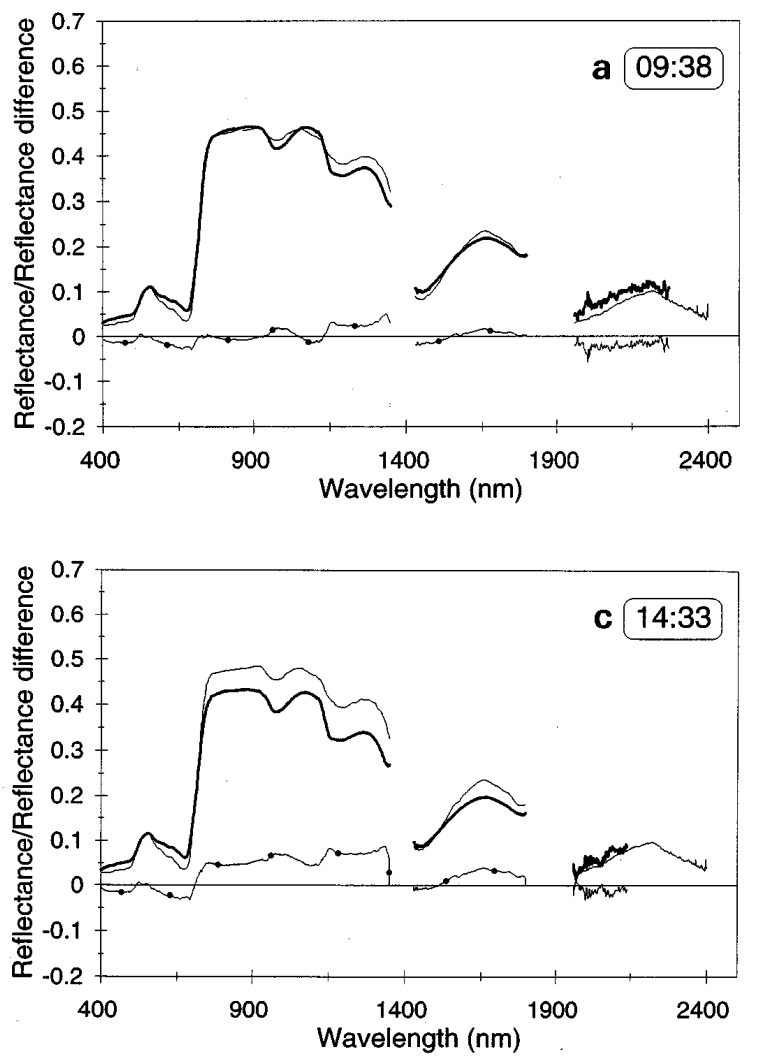

of around 2-3\% (Fig. 6a). The model underestimated red reflectance by approximately $2.5 \%$ (Fig. 3), a small absolute difference but large when compared with the magnitude of reflectance at red wavelengths. At 12:02 measured and modelled reflectance were similar (Fig. 6b) although red reflectance was again underestimated and near infrared reflectance overestimated (Fig. 3). By 14:33 differences between the measured and modelled spectrum were larger with the model overestimating reflectance by $3-5 \%$ in the near infrared (Fig. 6c). By 16:33 this difference was larger with the model overestimating reflectance in the near infrared by $10 \%$ and by a maximum of $5 \%$ in the middle infrared (Fig. 6d). In the near infrared the measured reflectance decreased during the day from 0.46 to 0.40 , a fall of $6 \%$ whereas the model
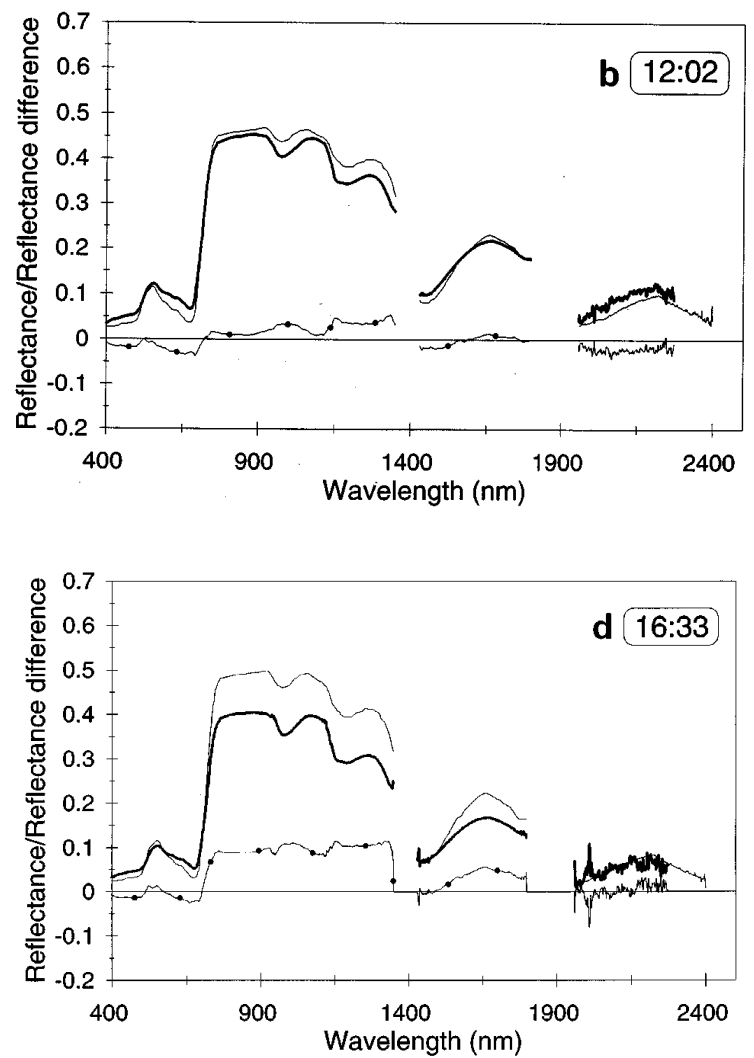

Figure 6. Comparison between measured (thick line) and modelled reflectance (thin line) at a) 09:38, b) 12:02, c) 14:33 and d) 16:33. Dotted lines indicate reflectance difference. 
predicted an increase in reflectance over the day of about $3 \%$. In the visible and middle infrared region the change in measured and modelled reflectance was small during the day but the model underestimated reflectance by up to $3 \%$ at red wavelengths.

The poor fit between measured and modelled spectra is thought to be due to a number of factors. The SAIL model assumes a turbid medium and cannot therefore account for changes in gap fraction caused by "clumping". This may have caused an increase in canopy gap fraction as discussed in the previous section. A second cause of differences between measured and modelled spectra may be the spectral contribution of the leaf stems or petioles. These have been estimated to account for around $15 \%$ of the total leaf area in sugar beet but were not accounted for in this work [3]. The petioles have low chlorophyll concentration and high visible reflectance and change in the fraction of petioles in the sensors field of view may account for some of the differences between measured and modelled spectra in visible wavelengths.

In addition to these effects, the contribution of specular reflectance was not accounted for in the model and may also have contributed to the poor model fit, particularly in visible wavelengths [3]. Futhermore, the work of Rollin et al. [11] showed that measurement errors in surface spectral reflectance may be introduced by the anisotropic reflectance characteristics of Spectralon reference panels. Although a first-order correction was applied in this work, the wavelength-dependence of the correction was not determined and the influence of change in the diffuse radiation field may have introduced errors into the spectral measurements.

\section{Conclusions}

Diurnal change in the reflectance of a water stressed sugar beet crop was affected by change in canopy geometry and change in the canopy gap fraction caused by leaf curling and drooping. Change in the solar zenith angle during the day affected the amount of shadow within the canopy, particular in visible wavelengths, and this was confounded with these affects. The Prospect+SAIL model has been used successfully to model the spectral response of a range of crop canopies. However, this experiment shows that it may not be suitable for modelling the diurnal spectral response of water stressed sugar beet where change in solar position is accompanied by a change in canopy architecture. It is likely that the assumption of a turbid scattering medium is not met by this canopy and that the degree of clumping of the foliage changes with wilting.

The main implication of this work is that biophysical estimates of sugar beet canopy biophysical variables using vegetation indices or radiative transfer model inversion are likely to be inaccurate when the canopy experiences short-term water stress. Diurnal change in the normalised difference vegetation index, for example, will lead to an underestimation of canopy LAI in water-stressed conditions (because near infrared reflectance decreases), as will the inversion of the combined Prospect+SAIL model. If estimates of LAI derived under such conditions are introduced into yield prediction models, then yield could be underestimated. However, reflectance changes caused by diurnal water stress in sugar beet are more important after midday. Reflectance measurements obtained mid-morning, as is the case for data from many satellite sensors, may be relatively unaffected unless the level of water stress is very high. Further work in progress aims to simulate the three-dimensional variation in canopy geometry with a geometric-optical model which will be used to examine the factors controlling the diurnal reflectance changes in sugar beet crops in more detail.

Acknowledgements: We acknowledge the Natural Environment Research Council Equipment Pool for Field Spectroscopy for the loan of the spectroradiometer, Mr Irving of Marsh Farm, Rostherne for allowing us access to the sugar beet crop and Neil Higgins and Earnest Nama for assistance with the field work. FMD acknowledges the Royal Society for support for a study visit to INRA, Avignon and Dr Fréderic Baret for his help during the visit. 


\section{References}

[1] Aldakheel Y.Y., Danson F.M., Spectral reflectance of dehydrating leaves: measurements and modelling, Int. J. Remote Sens. 18 (1997) 3683-3690.

[2] Andrieu B., Boissard P., Évolution diurne de la réflectance d'un couvert à géométrie variable : la betterave à sucre. Conséquences pour l'interprétation des mesures radiométriques, Bull. Soc. Fr. Photogramm. et Télédétect. 103 (1986) 25-31.

[3] Andrieu B., Baret F., Jacquemoud S., Malthus T.J., Steven M.D., Evaluation of an improved version of SAIL model for simulating bidirectional reflectance of sugar beet canopies, Remote Sens. Environ. 60 (1997) 247-257.

[4] Baret F., Clevers J.G.P.W., Steven M.D., The robustness of canopy gap fraction estimates from red and near-infrared reflectances: a comparison of approaches, Remote Sens. Environ. 54 (1995) 141-151.

[5] Collier P., Radiometric monitoring of moisture stress in irrigated cotton, Int. J. Remote Sens. 10 (1989) 1445-1450.

[6] Danson F.M., Steven M.D., Malthus T.J., Clark J.A., High spectral resolution data for monitoring leaf water content, Int. J. Remote Sens. 13 (1992) 461-470.
[7] Goel N.S., The application of canopy reflectance models for estimation of biophysical parameters from reflectance data, in : Asrar G. (Ed.), Theory and Applications of Optical Remote Sensing, Wiley, New York, 1989, pp. 205-251.

[8] Jackson R.D., Ezra C.E., Spectral response of cotton to suddenly induced water stress, Int. J. Remote Sens. 6 (1995) 177-185.

[9] Jacquemoud S., Baret F., Andrieu B., Danson F.M., Jaggard K.W., Extraction of vegetation biophysical parameters by inversion of PROSPECT+SAIL model on sugar beet canopy reflectance data. Application to TM and AVIRIS sensors, Remote Sens. Environ. 52 (1995) 163-172.

[10] Kuusk A., The hot-spot effect in plant canopy reflectance, in: Myneni R.B., Ross J., (Eds.), Photon Vegetation Interaction, Springer Verlag, Berlin, 1991, pp.140-159.

[11] Rollin E.M., Emery D.A., Milton E.J., Reference panel anisotropy and the significance of diffuse radiation, Proceedings 7 th International Symposium on Physical Measurements and Signatures in Remote Sensing, Courchevel, France 6-11 April 1997, Centre National d'Etudes Spatiales, Paris, 1997, pp. 143-149.

[12] Steven M.D., Jaggard K.W., Advances in crop monitoring by remote sensing, in: Danson F.M., Plummer S.E. (Eds.), Advances in Environmental Remote Sensing, Wiley, Chichester, 1995, pp. 143-156. 